\title{
PERBANDINGAN KADAR NITRIT PADA KORNET DAGING SAPI SEBELUM DAN SUSUDAH DIKUKUS YANG DIJUAL DI WILAYAH KECAMATAN MATRAMAN
}

\author{
*Yuli Kristiangsih ${ }^{1)}$, Eka Fitrianti' ${ }^{1)}$ \\ ${ }^{1}$ Program Studi D III Analis Kesehatan, Fakultas Kesehatan, Universitas Mohammad Husni Thamrin \\ Correspondence author: Yuli Kristianingsih, yulikristianingsih21@gmail.com, Jakarta, Indonesia
}

\begin{abstract}
ABSTRAK
Daging kornet adalah daging yang diawetkan dalam air garam dan kemudian di masak dengan cara direbus. Daging ini diketahui sebagai bahan yang mudah rusak karena itu perlu adanya pengawet seperti Nitrit. Nitrit merupakan salah satu bahan pengawet yang digunakan dalam proses pengawetan daging untuk memperoleh warna yang baik dan menghindari pertumbuhan Clostridium botulinum. Proses pemanasan dapat menyebabkan terjadinya reaksi kimia yang merubah nitrat menjadi nitrit. Penelitian ini bertujuan untuk mengetahui perbandingan kadar nitrit kornet daging sapi mentah dan matang yang berada diwilayah kecamatan Matraman. Batas kadar maksimum untuk daging olahan menurut Peraturan Kepala Badan Pengawas Obat dan Makanan Republik Indonesia No. 36 tahun 2013, yaitu sebesar $30 \mathrm{mg} / \mathrm{kg}$. Pemeriksaan sampel menggunakan uji kualitatif dan uji kuantitatif metode spektrofotometri dengan panjang gelombang $530 \mathrm{~nm}$. Penelitian dilakukan terhadap 20 sampel kornet daging sapi yang terdiri 10 sampel sebelum dikukus dan 10 sampel sesudah dikukus. Kadar seluruh sampel masih sesuai peraturan BPOM RI No. 36 tahun 2013, kadar nitrit tertinggi kornet daging sapi sebelum dikukus yaitu 7,75 ppm dan terendah 5,35 ppm. Sedangkan kadar nitrit tertinggi kornet daging sapi sesudah dikukus yaitu 11,76 dan terendah $8,34 \mathrm{ppm}$. Berdasarkan uji statistik diatass didapatkan nilai $\mathrm{p}$ value (signifikan) adalah $0,000<0,05$ dan didapatkan t hitung yaitu $-5,607$ dengan t tabel 2,1009, maka $\mathrm{H}_{\mathrm{o}}$ ditolak yang artinya bahwa ada perbedaan antara kadar nitrit pada kornet daging sapi sebelum dan sesudah dikukus.
\end{abstract}

Kata Kunci : Kornet, Kadar Nitrit, Bahan Tambahan Makanan

\section{ABSTRACT}

Corned beef is meat that is preserved in brine and then cooked in a boiled manner. This meat is known as a perniable ingredient because it needs preservatives such as Nitrite. Nitrites are one of the preservatives used in the meat preservation process to obtain a good color and avoid the growth of Clostridium botulinum. The heating process can cause a chemical reaction that converts nitrates into nitrites. This research aims to find out the comparison of corned beef and ripe corned nitrite levels located in matraman sub-district. The maximum content limit for processed meat according to the Regulation of the Head of the Food and Drug Control Board of the Republic of Indonesia No. 36 of 2013, which is $30 \mathrm{mg} / \mathrm{kg}$. Sample examination uses qualitative testing and quantitative testing of spectrophotometric methods with wavelengths of $530 \mathrm{~nm}$. The study was conducted on 20 beef corned beef samples consisting of 10 samples before being processed and 10 samples after being processed. The whole sample level is still in accordance with BPOM RI Regulation No. 36 of 2013, the highest level of corned beef corned beef before being processed is $7.75 \mathrm{ppm}$ and the lowest is $5.35 \mathrm{ppm}$. While the highest level of corned beef corned beef after being processed was 11.76 and the lowest was 8.34 ppm. Based on the statistical test above obtained a $p$ value (significant) value is $0.000<0.05$ and obtained t count of $-5,607$ with $t$ table 2.1009, then Ho is rejected which means that there is a difference between the level of nitrites in corned beef before and after the processed.

Keywords : Corned beef, Nitrite Content, Food Add-ons

Open Journal System (OJS): journal.thamrin.ac.id

http://journal.thamrin.ac.id/index.php/anakes/issue/view/33 


\section{PENDAHULUAN}

Pangan merupakan kebutuhan dasar yang sangat penting bagi kehidupan setiap insan baik secara fisiologis, psikologis, sosial maupun antropologis. Pangan selalu terkait dengan upaya manusia untuk mempertahankan hidupnya. Oleh karena itu, pemerintah Indonesia sejak orde baru sangat mempertahankan peranan strategis pangan dalam pembangunan nasionalnya. Untuk mendukung upaya ini, di samping usaha-usaha untuk terus meningkatkan produksi komoditas pertanian secara ekstensif, dikembangkan program diverifikasi untuk mendapatkan suatu pola komsumsi pangan yang beragam dengan mutu gizi yang seimbang (Wirakartakusumah, 2001).

Berdasarkan ketentuan umum Badan Pengawasan Obat dan Makanan Republik Indonesia (BPOM RI) No. 36 tahun 2013, pengertian pangan adalah segala sesuatu yang berasal dari sumber hayati produk pertanian, perkebunanan, kehutanan, perikanan, perairan dan air, baik yang diolah maupun yang tidak diolah yang diperuntukan sebagai makanan atau minuman bagi konsumsi manusia, termasuk bahan tambahan pangan, bahan baku pangan, dan bahan lainnya yang digunakan dalam proses penyiapan, pengolahan, dan/atau pembuatan makanan dan minuman (BPOM RI, 2013).

Bahan Tambahan Makanan (BTM) atau sering disebut Bahan Tambahan Pangan (BTP) adalah bahan yang ditambahkan ke dalam makanan untuk mempengaruhi sifat ataupun bentuk makanan. Menurut Peraturan Badan Pengawasan Obat dan Makanan RI Nomor 36 Tahun 2013, pengawet adalah Bahan Tambahan Makanan untuk mencegah atau menghambat fermentasi, pengasaman, penguraian, dan perusakan lainnya terhadap makanan yang disebabkan oleh mikroorganisme (BPOM RI,2013).

Nitrit atau natrium nitrit paling utama digunakan sebagai bahan tambahan makanan yang digunakan sebagai anti mikroba untuk menghambat pertumbuhan dan produksi toksin dari Clostridium botulinum dalam daging yang diawetkan (Tahir S, 2006).

Penggunaan natrium nitrit sebagai pengawet untuk mempertahankan warna daging ternyata menimbulkan efek yang berbahaya bagi kesehatan, karena nitrit dapat berikatan dengan amino dan amida yang membentuk turunan nitrosamin yang bersifat toksik. Nitrosamin merupakan salah satu senyawa yang diduga dapat menimbulkan kanker (Cahyadi ,2006).

Pemakaian bahan pengawet dari satu sisi menguntungkan karena dengan bahan pengawet, bahan pangan dapat disebabkan dari kehidupan mikroba, baik yang bersifat patogen yang dapat menyebabkan keracunan atau gangguan kesehatan lainnya maupun mikroba yang nonpatogen yang dapat menyebabkan kerusakan bahan pangan, misalnya pembusukan namun dari sisi lain, bahan pengawet pada dasarnya adalah senyawa kimia yang merupakan bahan asing yang masuk bersama bahan pangan yang dikonsumsi apabila pemakaian bahan pangan dan dosisnya tidak teratur dan diawasi. Kemungkinan besar akan menimbulkan kerugian bagi pemakainya (Cahyadi, 2008).

Open Journal System (OJS): journal.thamrin.ac.id 
Konsumsi nitrit yang berlebihan juga dapat menyebabkan keracunan. Pada tahun 1989 ditemukan kasus keracunan pada biskuit yang mengakibatkan kematian 38 jiwa manusia. Kasus ini terjadi karena mereka mengkonsumsi biskuit yang mengandung natrium nitrit dalam taraf yang melebihi batas yang diijinkan (Yulianti,2007).

Kornet adalah produk olahan daging sapi dengan teknologi perlakuan pendahuluan curing yang dimasak secara steaming dengan suhu $80^{\circ} \mathrm{C}$ (Abrianto, 2011). Kornet daging sapi atau corned beef merupakan hasil olahan daging sapi dengan bumbu-bumbu kentang, kaldu (beef broth), bawang merah, garam merica, dan sodium nitrat $\left(\mathrm{NaNO}_{2}\right)$. Faktor-faktor yang mempengaruhi kualitas daging kornet : jenis daging, mutu bahan baku, cara pengolahan, cara dan lama penyimpanan, kondisi kaleng selama penyimpanan. Masa simpan kornet kaleng tergantung dengan proses pengolahan, jenis kaleng, penyimpanan dan distribusi. Kornet dibuat untuk mengawetkan daging melalui proses curing oleh peranan garam curing. Curing bisa menjadi prekusor terjadinya karsinogenik karena akan bereaksi senyawa nitrosamin (Fardiaz, 2008).

Kornet daging sapi dapat disimpan dalam kemasan kaleng dan dengan melalui proses sterilisasi akan bertahan selama 2 tahun atau lebih, karena kornet kornet merupakan produk setengah jadi maka setelah dikeluarkan dari kemasan kornet harus melalui proses pemasakan terlebih dahulu (Direktorat Gizi Depkes, 1992).

Pada pembuatan kornet, bahan pengawet yang sering digunakan adalah Nitrit. Aktifitas antibakteri Nitrit telah diuji dan ternyata efektif untuk mencegah pertumbuhan bakteri Clostridium botulinum, yang dikenal sebagai bakteri patogen penyebab keracunan makanan. Nitrit dapat menghambat pertumbuhan dan perkembangan spora Clostridium botulinum, Clostridium perferingens, dan Stapylococcus aureus pada daging yang diproses (Departemen Teknologi Pangan dan Gizi IPB, 2008).

Berdasarkan BPOM RI No. 36 Tahun 2013 tentang bahan tambahan, membatasi penggunaan maksimum pengawet nitrit di dalam produk daging olahan yaitu sebesar $30 \mathrm{mg} / \mathrm{kg}$. Keracunan nitrit dapat terjadi karena penggunaan yang melewati batasan maksimum.

Rifqi Anisa melakukan penelitian terhadap kadar Nitrit pada 8 sampel sosis dan kornet tahun 2017 di Jakarta. Hasil uji kualitatif seluruh sampel sosis dan kornet mengandung bahan pengawet nitrit. Kharisma Ulfah Arjani juga melakukan penelitian terhadap kadar Nitrit pada 10 sampel sosis sapi mentah dan matang tahun 2017 di Jakarta. Hasil uji kuantitatif seluruh sampel sosis mentah dan matang kadar Nitritnya masih memenuhi persyaratan. Berdasarkan permasalahan yang telah diuraikan di atas maka penulis melakukan Perbandingan Kadar Nitrit Pada Kornet Daging Sapi Seebelum dan Seseudah Di Kukus Yang Di Jual Di Wilayah Kecamatan Matraman. Oleh karena itu, penulis 
mengambil perbandingan judul “ Perbandingan Kadar Nitrit Pada Kornet Daging Sapi Sebelum dan Sesudah DiKukus Yang DiJual Di Wilayah Kecamatan Matraman”.

\section{METODE PENELITIAN}

Penelitian dilakukan pada bulan Juli 2018 di Laboratorium Kimia Makanan dan Minuman Fakultas Kesehatan Universitas MH. Thamrin Jakarta Timur.Populasi yang digunakan dengan penelitian ini adalah kornet daging sapi sebelum dan sesudah dikukus yang dijual di wilayah Kecamatan Matraman Jakarta Timur. Sampel yang diteliti sebanyak 10 sampel kornet daging sapi.

Data dari penelitian ini adalah data hasil pemeriksaan kadar nitrit pada daging kornet sebelum dan sesudah dikukus sebanyak 10 sampel dan masing-masing sampel dilakukan pengulangan pemeriksaan sebanyak 2 kali. Hasil analisa data daging kornet mengacu pada Peraturan Kepala Badan Pengawas Obat dan Makanan RI Nomor 36 Tahun 2013, yang mensyaratkan kadar nitrit dalam kornet $30 \mathrm{mg} / \mathrm{kg}$. Data diolah dengan perhitungan statistik kurva baku. Perbandingan kadar nitrit dalam kornet daging sapi sebelum dan sesudah dikukus.

\section{HASIL DAN PEMBAHASAN}

\section{Hasil}

\section{Uji kualitatif}

Hasil penelitian uji kualitatif yang dilakukan terhadap 20 sampel diperoleh hasil penelitian bahwa semua sampel daging kornet positif mengandung nitrit.

\section{Tabel 3}

Data Hasil Uji Kualitatif Sampel Daging Kornet

\begin{tabular}{|l|l|l|l|l|}
\hline \multirow{2}{*}{ No } & \multicolumn{2}{|l|}{ Sampel } & $\begin{array}{l}\text { Uji kualitatif } \\
\text { (warna ung } \\
\text { hilang) }\end{array}$ & Hasil \\
\hline \multirow{2}{*}{1} & \multirow{2}{*}{ Corned 8888 } & Sampel 1 & Ungu hilang & Positif \\
\cline { 3 - 5 } & & Sampel 2 & Ungu hilang & Positif \\
\hline 2 & \multirow{2}{*}{ Pronas pedas } & Sampel 1 & Ungu hilang & Positif \\
\cline { 3 - 5 } & & Sampel 2 & Ungu hilang & Positif \\
\hline 3 & \multirow{2}{*}{ Pronas keju } & Sampel 1 & Ungu hilang & Positif \\
\cline { 3 - 5 } & & Sampel 2 & Ungu hilang & Positif \\
\hline 4 & \multirow{2}{*}{ Pronas } & Sampel 1 & Ungu hilang & Positif \\
\cline { 3 - 5 } & & Sampel 2 & Ungu hilang & Positif \\
\hline 5 & \multirow{2}{*}{ CIP } & Sampel 1 & Ungu hilang & Positif \\
\cline { 3 - 5 } & & Sampel 2 & Ungu hilang & Positif \\
\hline
\end{tabular}




\begin{tabular}{|l|l|l|l|l|}
\hline 6 & \multirow{2}{*}{ Kornetku } & Sampel 1 & Ungu hilang & Positif \\
\cline { 3 - 5 } & & Sampel 2 & Ungu hilang & Positif \\
\hline 7 & \multirow{2}{*}{ Ajiib corn } & Sampel 1 & Ungu hilang & Positif \\
\cline { 3 - 5 } & & Sampel 2 & Ungu hilang & Positif \\
\hline 8 & \multirow{2}{*}{ Ajiib beef } & Sampel 1 & Ungu hilang & Positif \\
\cline { 3 - 5 } & & Sampel 2 & Ungu hilang & Positif \\
\hline 9 & \multirow{2}{*}{ King } & Sampel 1 & Ungu hilang & Positif \\
\cline { 3 - 5 } & & Sampel 2 & Ungu hilang & Positif \\
\hline 10 & \multirow{2}{*}{ Vigo } & Sampel 1 & Ungu hilang & Positif \\
\cline { 3 - 5 } & & Sampel 2 & Ungu hilang & Positif \\
\hline
\end{tabular}

\section{Uji kuantitatif}

Hasil penelitian yang dilakukan terdapat kadar nitrit pada sampel kornet daging sapi sebelum dan sesudah dikukus semuanya masih memenuhi persyaratan.

\section{Tabel 4}

Hasil Perbandingan Kadar Nitrit pada Kornet Daging Sapi Sebelum dan Sesudah Dikukus

\begin{tabular}{|c|c|c|c|c|c|}
\hline \multirow[t]{2}{*}{ No } & \multirow[t]{2}{*}{ Sampel } & \multicolumn{2}{|c|}{ Kornet sebelum dikukus } & \multicolumn{2}{|c|}{ Kornet sesudah dikukus } \\
\hline & & $\begin{array}{c}\text { Kadar Nitrit } \\
(\mathrm{mg} / \mathrm{kg})\end{array}$ & Keterangan & $\begin{array}{c}\text { Kadar Nitrit } \\
(\mathrm{mg} / \mathrm{kg})\end{array}$ & Keterangan \\
\hline 1 & Corned 8888 & 8,78 & Memenuhi syarat & 11,58 & $\begin{array}{c}\text { Memenuhi } \\
\text { syarat }\end{array}$ \\
\hline 2 & Pronas pedas & 7,36 & Memenuhi syarat & 10,09 & $\begin{array}{l}\text { Memenuhi } \\
\text { syarat }\end{array}$ \\
\hline 3 & Pronas keju & 7,38 & Memenuhi syarat & 10 & $\begin{array}{c}\text { Memenuhi } \\
\text { syarat }\end{array}$ \\
\hline 4 & Pronas & 8,62 & Memenuhi syarat & 13,13 & $\begin{array}{c}\text { Memenuhi } \\
\text { syarat }\end{array}$ \\
\hline 5 & CIP & 7,23 & Memenuhi syarat & 9,9 & $\begin{array}{c}\text { Memenuhi } \\
\text { syarat }\end{array}$ \\
\hline 6 & Kornetku & 9,03 & Memenuhi syarat & 13,20 & $\begin{array}{c}\text { Memenuhi } \\
\text { syarat }\end{array}$ \\
\hline 7 & Ajiib corn & 6,94 & Memenuhi syarat & 8,99 & $\begin{array}{c}\text { Memenuhi } \\
\text { syarat }\end{array}$ \\
\hline 8 & Ajiib beef & 7,02 & Memenuhi syarat & 9,23 & $\begin{array}{c}\text { Memenuhi } \\
\text { syarat }\end{array}$ \\
\hline 9 & King & 7,1 & Memenuhi syarat & 9,93 & $\begin{array}{c}\text { Memenuhi } \\
\text { syarat }\end{array}$ \\
\hline 10 & Vigo & 6,64 & Memenuhi syarat & 10,63 & $\begin{array}{c}\text { Memenuhi } \\
\text { syarat }\end{array}$ \\
\hline
\end{tabular}

Hasil penelitian yang dilakukan terhadap pemeriksaan kadar nitrit pada kornet daging sapi sebelum dan sesudah dikukus diperoleh hasil kadar nitrit dalam contoh dan dihitung dengan penetapan hasil serapan larutan kurva baku. data tersebut kemudian diolah menggunakan statistik Uji t, didapat asumsi sebagai berikut : 
$\mathrm{H}_{\mathrm{o}} \quad$ : Tidak ada perbedaan antara kadar nitrit pada kornet daging sapi sebelum dan sesudah dikukus.

$\mathrm{H}_{\mathrm{a}} \quad$ : $\quad$ Ada perbedaan antara kadar nitrit pada kornet daging sapi sebelum dan sesudah dikukus.

Tabel 5

Hasil Data Uji T Kadar Nitrit Pada Kornet Daging Sapi Sebelum dan Sesudah Dikukus

\begin{tabular}{|l|l|l|l|l|}
\hline \multicolumn{2}{|l|}{} & \multicolumn{1}{|c|}{$\mathrm{T}$} & \multicolumn{1}{c|}{ Df } & \multicolumn{1}{c|}{ Sig } \\
\hline Sebelum dikukus & $\begin{array}{l}\text { Equal variances } \\
\text { assumed }\end{array}$ & -5.607 & 18 & .000 \\
\hline Sesudah dikukus & 18 & \\
\hline
\end{tabular}

Berdasarkan uji statistik diatas didapatkan nilai $p$ value (signifikan) adalah $0,000<0,05$ dan didapatkan $\mathrm{t}$ hitung yaitu $-5,607$ dengan $\mathrm{t}$ tabel 2,1009, maka $\mathrm{H}_{\mathrm{o}}$ ditolak yang artinya bahwa ada perbedaan antara kadar nitrit pada kornet daging sapi sebelum dan sesudah dikukus.

\section{Pembahasan}

Dari hasil penelitian yang dilakukan pada 10 sampel kornet daging sapi yang berada di Wilayah Kecamatan Matraman didapat bahwa kadar nitrit yang sebelum dan sesudah dikukus tidak melampaui batas maksimum yang diizinkan BPOM RI No 36 Tahun 2013, sehingga dapat dikonsumsi oleh masyarakat.

Natrium nitrit merupakan zat tambahan pangan yang digunakan sebagai pengawet pada pengolahan daging. Natrium nitrit sangat penting dalam mencegah pembusukan terutama untuk penyimpanan, transportasi dan distribusi produk-produk daging. Oleh karena itu dalam industri makanan kaleng penggunaan zat pengawet ini sangat penting karena dapat menyebabkan warna daging olahannya menjadi merah atau pink nampak segar.

Senyawa nitrit merupakan zat pengawet yang baik yang dapat mencegah pertumbuhan yang baik. Namun kelemahan zat pengawet nitrit adalah timbulnya senyawa nitrosamin yang diduga sebagai penyebab timbulnya kanker sehingga dihindari penggunaannya.

Nitrosamin merupakan hasil reaksi antara amin sekunder atau tersier dengan $\mathrm{NaNO}_{2}$ dalam medium yang bersifat asam. Nitrosamin dapat juga terbentuk dari nitrit yang beredar dalam tubuh manusia atau hewan.

Dari Pemeriksaan uji kualitatif dengan $\mathrm{H}_{2} \mathrm{SO}_{4}$ dan $\mathrm{KMnO}_{4}$ menunjukkan warna ungu hilang, hasil semua sampel kornet positif mengandung nitrit. Sedangkan uji kuantitatif dengan metode 
spektrofotometer didapatkan kadar nitrit tertinggi kornet daging sapi sebelum dikukus pada merk kornetku yaitu 9,03 ppm, dan kadar nitrit terendah terdapat pada merk Ajiib beef yaitu 7,02 ppm. Sedangkan kornet daging sapi sesudah dikukus didapatkan kadar nitrit tertinggi pada merk Kornetku yaitu 13,20 ppm, dan kadar nitrit terendah terdapat pada merk Ajiib corn yaitu 8,99 ppm.

Peningkatan kadar nitrit pada kornet daging sapi matang terjadi karena sudah ada pemanasan sebelumnya pada proses simmering. Simmering adalah teknik memasak bahan makanan dalam cair atau sauce yang dididihkan dahulu, lalu api dikecilkan dibawah titik didih dan direbus lama, dimana di permukaanya muncul gelembung-gelembung kecil. Secara umum proses pemanasan menyebabkan bahan pangan lebih awet serta menurunkan aktifitas air (penguapan). Apabila permukaan daging menjadi lebih kering karena penguapan air, maka konsentrasi garam nitrit akan meningkat dan merubah garam nitrat menjadi nitrit. Sehingga mengakibatkan terjadinya oksidasi pigmen daging (myoglobin) yang berwarna merah cerah menjadi metmioglobin dengan warna coklat yang bersifat warna permukaan daging menjadi lebih gelap (Purnomo, 2012).

Secara umum proses pemanasan bisa menyebabkan terjadinya reaksi kimia. Hal ini terjadi karena adanya tumbukan antar zat dalam suatu media akibat dari suatu pemanasan. Hal tersebut dapat terjadi apabila didalam media telah tersedia zat yang siap bereaksi, tanpa adanya proses pemanasan pertama, kedua dan seterusnya tidak akan menghasilkan suatu zat baru jika dalam media tidak terdapat zat pereaksi (Haryono, 2016).

Sementara nitrat terbentuk karena sudah ada proses pemanasan sebelum pada pengolahan kornet daging sapi. Nitrat dapat berubah menjadi racun bila terkena panas yang sangat tinggi. Saat nitrat terkena suhu panas yang tinggi maka akan terkonversi menjadi senyawa nitrosamin (Anonim, 2016). Senyawa nitrosamin berasal dari nitrit, karena nitrit dapat berikatan dengan amino dan amida yang membentuk turunan nitrosamin. Senyawa ini bersifat karsinogenik penyebab kanker (Cahyadi, 2006). Berdasarkan pemeriksaan ini, nitrit termasuk bahan pengawet yang diizinkan oleh pemerintah sebagai bahan tambahan pangan, namun keberadaan nitrit dalam pangan tidak boleh melebihi batas yang sudah diatur oleh pemerintah, untuk menhindari efek yang tidak diinginkan. Kadar nitrit pada kornet daging sapi dari berbagai toko di Wilayah Kecamatan Matraman semuanya masih dibawah $30 \mathrm{mg} / \mathrm{kg}$, artinya kadar nitrit dalam kornet daging sapi sudah memenuhi peraturan yang di tetapkan Badan Pengawas Obat dan Makanan Republik Indonesia No.36 Tahun 2013 yaitu 30 mg/kg. Produsen kornet daging sapi sudah mengikuti aturan yang telah ditetapkan pemerintah demi keamanan pangan bagi konsumen.

Open Journal System (OJS): journal.thamrin.ac.id 


\section{Simpulan}

Terjadi peningkatan kadar nitrit pada kornet daging sapi setelah dilakukan pemanasan (kukus). Sampel daging kornet mentah dan matang pada pemeriksaan nitrit dari 5 toko swalayan yang berada di Kecamatan Mtraman Jakarta Timur masih memenuhi syarat peraturan Kepala Badan Pengawas Obat dan Makanan Republik Indonesia Nomor 36 Tahun 2013 untuk daging olahan sebesar 30 mg/kg. Hasil Uji t ada perbedaan antara kadar nitrit pada kornet daging sapi sebelum dan sesudah dikukuks.

\section{UCAPAN TERIMA KASIH}

Penulis mengucapkan terima kasih kepada Kepala Laboratorium Kimia Pangan Fakultas Kesehatan Universitas Mh.Thamrin Jakarta dan Prodi D III Analis Kesehatan Fakultas Kesehatan Universitas MH Thamrin. dalam penelitian ini.

\section{DAFTAR PUSTAKA}

1. Abrianto. W. W,P 2011. Sejarah Kornet Daging Sapi, Universitas Muhammadyah Semarang. Semarang.

2. Aswatan M. 2004. Kandungan Daging Sapi . PT. Gramedia Pustaka Utama. Jakarta.

3. Breysse, PN dan Lees, PSJ, 2003. Analysis of Gates and Vapors, American Industrial Hygen Assosiation. Press.

4. Cahyadi, Wisnu. 2006. Analisis dan Aspek Kesehatan Bahan Tambahan Pangan. PT Bumi Aksara, Jakarta.

5. Departemen Kesehatan RI, 2013. Peraturan Badan Pengawas Obat dan Makanan Nomor 36 Tahun 2013, tentang Batas Maksimum Penggunaan Bahan Tambahan Pangan Pengawet.

6. Departemen Teknologi Pangan dan Giz, Intstitut Pertanian Bogor, 2008. Bogor.

7. Desroiser, W. 1988. Teknologi Pengawetan Makanan. Jakarta.

8. Direktorat Gizi Departement Kesehatan, 1992. Karakteristik Daging Sapi Olahan. Jakarta.

9. Dr. Ir. Wisnu Cahyadi, M.si., 2008, Bahan Tambahan Pangan, Jakarta, PT. Bumi Aksara.

10. Effendi, Muh , Arief, 2009. The Power of Corporate Goverment : teori dan implementant. Jakarta.

11. Fardiaz S, 2008. Produksi Pigmen Untuk Bahan Pewarna Makanan, Intritut Pertanian Bogor. Bogor.

12. Hafizha, M, Dampak Penggunaan Natrium Nitrit Terhadap Kesehatan , 2013.

13. Haryono, Agus, KA. Penelitian Kimia. Lembaga Ilmu Pengetahuan Indonesia (LPI) . Merebus ulang air yang sudah matang bisa sebebkan keracunan. Tersedia https://m.detik.com/news/berita/3150816/merebus-ulang-air-yang-sudah-matang-bisasebabkan-keracunan (Diakses 28 Agustus 2018)

Open Journal System (OJS): journal.thamrin.ac.id

http://journal.thamrin.ac.id/index.php/anakes/issue/view/33 
14. Lawrie, R.A.2003. Ilmu Daging Terjemahan : A. Praktis. Universitas Indonesia Press. Jakarta.

15. Lestari, Msi, PhD, 2007. Bahan Tambahan Pangan, Jakarta. PT Bumi Askara.

16. Muchtadi, T.R , Sugiyono, dan Ayustaningwarno, F., Ilmu Pengetahuan Bahan Pangan, Alfabeta, C., Bandung, 2010.

17. Nita,Theresia. 2011. Kornet. Universitas Muhamadyah Semarang. Semarang.

18. Nurwantoro dan A. S. Djariah, 1997. Mikrobiologi Hewan dan Nabati. Yogyakarta.

19. Prof. Dr. Ir. M. aman Wirakartakusumah, MSc. 2001. Ilmu Teknologi Pangan. Fakultas Institut Bogor. Bogor.

20. Purnomo, Hari. Teknologi pengolahan dan pengawetan daging. Cetakan pertama, UB Press, 2012.

21. Rifqi, Annisa. 2014 "Analisa Kualitatif Kandungan Pengawet Dalam Sosis Dan Kornet” Tersedia http://www.academia.edu/7244792/ANALISA_KUALITATIF_KANDUNGAN_NITR AT_NITRIT_DALAM_SOSIS_DAN_KORNET_BERBAGAI_MERK (Diakses 10 September 2018).

22. Soeparno, 1998. Ilmu dan Teknologi Daging. Gajah Mada University Press, Yogyakarta.

23. Standar Nasional Indonesia, No 01-2891-1992, Badan Standarisasi Nasional, Jakarta, 1992.

24. Supartinah, Apt. 2015. Penuntun Praktikum Kimia Amami Semster IV - V, Jakarta.

25. Svehla, G., Vogel, Buku Teks Analisis Anorganik Kualitatif Makro dan Semimikro, Bagian II, Edisi V, diterjemahkan oleh Setiono, Pudjaatmaka, PT Kalman Media Pusaka, Jakarta, 1990.

26. Tahir, Syahril.2006. Bahan Tambahan Pangan, Jakarta.

27. Yuliarti. 2007. Jenis Daging Olahan Nitrit. Jarakta. 